\title{
Conformation of Hind Legs and Lameness in Danish Holstein Heifers
}

\author{
N. Capion, ${ }^{\star 1}$ S. M. Thamsborg, $†$ and C. Enevoldsen* \\ *Department of Large Animal Sciences, and \\ †Department of Veterinary Pathobiology, Faculty of Life Sciences, University of Copenhagen, Bülowsvej 17, \\ DK-1870 Frederiksberg C, Denmark
}

\begin{abstract}
Lameness causes major financial losses and welfare problems in dairy herds. Prevention of foot lesions may suffice in the majority of lameness cases. The objectives of this longitudinal study were to describe the dynamics and associations between abnormal hind leg conformation, asymmetric claws, lameness, and foot lesions in 122 Danish Holstein heifers from an average of $41 \mathrm{~d}$ before first calving until dry off or culling. The cattle were housed either in a free-stall system with cubicles or in deep-bedded straw yard. The claws of all cattle were examined on up to 5 occasions. The associations between foot lesions, lameness, symmetry of the claws, shape of the dorsal toe-wall, and the conformation of the hind legs were examined statistically using mixed models. A large proportion (81\%) of the heifers had cowhocked conformation, with wide-based stance, hocks together, and lateral rotation of the foot before calving, and $25 \%$ of the heifers had locomotion scores above 2, indicating signs of lameness, before calving. Our results indicate that lameness, abnormal conformation, and lesions acquired precalving persist throughout the first lactation. Thinner cows were more cow-hocked, and cow-hocked cows had a higher frequency of sole hemorrhages. Increased severity of white line lesion was associated with greater claw asymmetry. More severe lameness and sole hemorrhages were found in symmetric claws.
\end{abstract}

Key words: dairy heifer, hindleg conformation, lameness, claw lesion

\section{INTRODUCTION}

Clinical lameness has a negative impact on milk yield and fertility (Hernandez et al., 2001; Green et al., 2002) as well as being a painful condition that decreases animal welfare. Foot lesions are the most frequent causes of lameness (Jubb and Malmo, 1991). Consequently,

Received July 18, 2006.

Accepted January 7, 2008.

${ }^{1}$ Corresponding author: nyc@life.ku.dk lameness and foot lesions cause financial and welfare problems in modern dairy production (Kossaibati and Esslemont, 1997; O'Callaghan et al., 2003). Most (90.5 to $96.3 \%$ ) lameness cases are caused by diseases of the claws and the digital skin (Jubb and Malmo, 1991; Hernandez et al., 2001). Hind claws are usually more affected than front claws; lateral claws tend to be more affected on the hind legs and medial claws more affected on the front legs (Bergsten, 1994; Vermunt and Greenough, 1996b). Frequently, the horn lesions seem to occur bilaterally (Le Fevre et al., 2001). Furthermore, Enevoldsen et al. (1991) speculated that bilateral lesions reflect a systemic disorder, whereas unilateral horn lesions represent a traumatic incident.

The weight distribution on claws is determined by the position of the hind legs (Toussaint-Raven, 1985). A normal parallel stance provides a more even weight distribution between the medial and lateral claws compared with a cow-hocked stance, with wide-based stance, hocks together, and lateral rotation of the foot, where the sole of the lateral claws on the hind legs receives the majority of the load compared with the wall (van der Tol et al., 2002). This cow-hocked condition may also lead to asymmetrical claws. Alterations in the weight-bearing area of the claw may predispose the affected cow to lesions and lameness. ToussaintRaven (1985) speculated that the cow-hocked stance was, to a great extent, an adopted posture due to overgrown sole, housing, and claw lesions. Several studies have later described cow-hocked posture as a heritable condition (Andersen et al., 1991; Brotherstone and Hill, 1991). The cow-hocked posture has been associated with increased clinical lameness (Boettcher et al., 1998). Whether the cows develop the cow-hocked posture as a response to pain in the lateral claw or the lesions in the lateral claw develop because of the cowhocked posture is still unclear.

In addition, it has been shown that a concave toewall is a sign of chronic laminitis from a rotation of the distal phalanx (Peterse, 1985); however, whether toewall concavity is related to other factors remains unknown.

Most studies of lameness, foot lesions, and conformation traits are based on a single examination of the 
animals and rarely include all of these manifestations simultaneously. The objectives of this longitudinal study were to describe the dynamics and associations between abnormal hind leg conformation, asymmetric claws, lameness, and foot lesions in heifers during their introduction to the milking herd.

\section{MATERIALS AND METHODS}

The study was designed as a prospective longitudinal study of Danish Holstein cattle before and after first calving. A total of 147 cattle from 5 herds was included in the study. In herd 1 , the cattle were confined in tie stalls before calving and in cubicle housing with a slatted concrete floor after calving. In herds 2 and 5, the cattle were housed on a deep-bedded straw yard with slatted concrete floors at the feed-bunk before calving. After calving, the cattle from these herds were moved to a similar deep-bedded straw yard with a combination of solid and slatted concrete floors in all alleys. In herds 3 and 4 , the cattle were housed in a free-stall system with cubicles and slatted concrete floors in walking areas both before and after calving.

The heifers were examined 2 to 5 times at 3 -mo intervals. At each examination, the heifers were photographed from side and rear views. The hind legs were scored from side and rear views based on available or modified scoring systems (Table 1). Body condition was scored visually according to Ferguson et al. (1994).

Locomotion (Sprecher et al., 1997) and hind leg conformation were scored in all cattle, based on observations of standing and walking in the cattle's environment before going to the claw-trimming chute. In the trimming chute, all claws were washed and photographed, and all legs and claws were examined thoroughly for lesions, which were then scored for severity (Table 1). When $>50 \%$ of the claws were unpigmented, the claws were scored as unpigmented; otherwise, the claws were scored as pigmented. On the right front (RF) and right hind (RR) legs, all lesions and claw size (length and width) were photographed for later reference. Toe-length was measured on the medial claw of the RF and on the lateral claw of the RR. Subsequently, a thin slice of horn was trimmed from the sole to visualize lesions. Both claws on the $R F$ and $R R$ were photographed again after trimming. The profile or shape of the dorsal toe-wall was drawn for the RF and $R R$ to evaluate the concavity of the dorsal toe-wall. This was done by measuring the maximum perpendicular distance $(\mathrm{mm})$ from the toe-wall and a straight line from the coronary band to the tip of the toe. Positive values indicate a concave wall.

Calving date was recorded from the herds to calculate DIM. Observations that had missing values of one or more variables were excluded from the data file. This criterion reduced the data file from 147 heifers with 397 records to 122 heifers with 255 records. The analysis was restricted to cows with a complete set of records to allow comparison of variance components between models and during model reductions.

The data were recorded with ordinal scores ( 0 to 2 or 0 to 5 ) to provide more information. However, because many categories had none or only a few cases, regrouping was necessary in some instances. To calculate prevalences of clinically meaningful conditions, scores were dichotomized; for example, original scores 1 and 2 ( 3 to 5 ) were assigned a new score of 0 (1).

An initial 3-level (herd, animal, and time of measurement) linear regression model was specified for each conformation trait according to the principles applied by Bennedsgaard et al. (2003) as follows:

Trait $=$ Intercept $+\mathrm{DIM}+\mathrm{DIM}^{2}+\mathrm{DIM}^{3}+\mathrm{DIM}^{4}+\mathrm{X}_{1}$ $+\mathrm{X}_{2}+\ldots+\mathrm{X}_{\mathrm{x}}+$ relevant 2-way interactions + residual

where Trait was the response variable and the analysis was performed for all of the following variables: lameness, cow-hock, hock angle, asymmetry of claw, toewall $R F$, toe-wall $R R$, toe-length $R F$, toe-length $R R$, and BCS. The intercept comprised

1) A fixed effect that represents the mean score at zero-values of the explanatory values [e.g., DIM = 0 or centered quantitative $(\mathrm{X})$ variables];

2) A random effect that represents the contributions from the individual cows within herds at zero-values of the explanatory values; and

3) A random effect that represents the contributions from the individual herds at zero-values of the explanatory values.

The random effects (including the residuals) were assumed to be normally distributed with zero means; DIM is the stage of lactation; $\mathrm{X}_{1}, \mathrm{X}_{2}, \ldots \mathrm{X}_{\mathrm{x}}$ indicate the other covariates included in the models (described in Table 1), and the specification is elaborated in the results and discussion section. The coefficients of this model were estimated by using Proc Mixed (SAS Institute, 2000). The model selection strategy was as follows. An initial "full model" with all explanatory variables (see below) and polynomials was reduced using backward selection by removing main effects and polynomials with $P$-values above approximately 0.2 . Finally, this model was reduced until all $P$-values were $\leq 0.05$. Attempts were made to estimate random effects of DIM; in other words, estimate if there were different relationships between the trait scores and DIM in different herds. However, 
Table 1. Definitions of recorded scores for conformation, lameness score, and foot lesions ${ }^{1}$

\begin{tabular}{|c|c|c|c|}
\hline Name & $\begin{array}{l}\text { Dichotomous } \\
\text { scale }\end{array}$ & $\begin{array}{l}\text { Names of new } \\
\text { categories }\end{array}$ & Definitions of recorded score categories \\
\hline \multirow[t]{3}{*}{ Cow-hock } & 0 & Normal & 0: Parallel posture \\
\hline & 1 & Cow-hocked & 1: Slightly outward rotation of the claws, parallel thighs \\
\hline & & & 3: Marked outward rotation, wide-based posture, thighs abducted \\
\hline \multirow[t]{2}{*}{ Hock angle } & 0 & Normal & 2: Normal angles \\
\hline & 1 & Abnormal hock angle & $\begin{array}{l}\text { 1: Narrow angles, sickle hock } \\
\text { 3: Wide angles, straight hocks }\end{array}$ \\
\hline \multirow{2}{*}{ Claw symmetry } & 1 & Asymmetric claw & 1: Asymmetric in length or width \\
\hline & & & 2: Asymmetric in length and width \\
\hline \multirow[t]{2}{*}{ Pigmentation } & 0 & No pigment & 0: Primarily unpigmented horn $(<50 \%)$ \\
\hline & 1 & Pigmented & 1: Primarily pigmented (black) horn $(>50 \%)$ \\
\hline \multirow[t]{2}{*}{ Lameness } & 0 & No or mild lameness & $\begin{array}{l}\text { 1-2: Stands and walks with level back posture or arches when } \\
\text { walks; gait is normal to slightly abnormal }\end{array}$ \\
\hline & 1 & $\begin{array}{l}\text { Moderate to severe } \\
\text { lameness }\end{array}$ & $\begin{array}{l}\text { 3-5: Stands and walks with arched back; short strides with lame } \\
\text { limb(s), limb(s) partially weight bearing or limb(s) not weight } \\
\text { bearing. }\end{array}$ \\
\hline Sole hemorrhage & 1 & Moderate to severe & $\begin{array}{l}\text { 3-5: Large }(>10 \%) \text { red or yellow discolorations penetrating } \\
\text { deep into the sole }\end{array}$ \\
\hline \multirow[t]{2}{*}{ White line lesion } & 0 & Nothing or mild lesions & $\begin{array}{l}0-2: \text { No lesions or superficial discolorations or separation in } \\
\text { the white line removed at normal trimming }\end{array}$ \\
\hline & 1 & Moderate to severe & 3-5: Deep discolorations, white line separation or abscess \\
\hline \multirow[t]{2}{*}{ Digital dermatitis } & 0 & No lesions & 0 : No lesions \\
\hline & 1 & $\begin{array}{l}\text { Lesions present on one } \\
\text { or more legs }\end{array}$ & $\begin{array}{l}\text { 1-2: Circumscribed erosive/ulcerative lesion in the digital skin; } \\
\text { one or more lesions }\end{array}$ \\
\hline \multirow[t]{2}{*}{ Sole ulcer } & 0 & No lesions & 0: No lesions \\
\hline & 1 & $\begin{array}{l}\text { Lesions present on one } \\
\text { or more legs }\end{array}$ & $\begin{array}{l}\text { 1: Exposed corium in the sole } \\
\text { 2: More than one claw affected }\end{array}$ \\
\hline \multirow[t]{2}{*}{ Double sole } & 0 & No lesions & 0: No lesions \\
\hline & 1 & $\begin{array}{l}\text { Lesions present on one } \\
\text { or more legs }\end{array}$ & $\begin{array}{l}\text { 1: Two separate distinct layers of sole horn } \\
\text { 2: More than one claw affected }\end{array}$ \\
\hline
\end{tabular}

${ }^{1}$ Data recorded as a nominal or ordinal score in the herds and dichotomized for analysis.

this was not possible due to the limited size of the data file. Model assumptions were checked by visual inspection of residual plots.

All lesions and hind leg conformation scores of 40 animals (blinded) were rescored by the first author from photographs selected at random by size of the data file. The reproducibility was evaluated by estimating weighted kappa values $(\mathbf{K})$ on the repeated scorings (Woodward, 1999). Agreement was considered not different from chance when $K=0$, and $K=1$ meant perfect agreement beyond chance agreement. Values between 0.4 and 0.75 are regarded as indicative of good agreement and values $>0.75$ represent excellent agreement (Woodward, 1999).

\section{RESULTS AND DISCUSSION}

\section{Data Quality and Model Validation}

Agreement was reasonably good between 2 independently recorded scorings of photographs by the first author for all lesions and conformation. The weighted kappa-values for the intra-observer variation were 0.59 [95\% confidence interval (CI): 0.19 to 0.69 ] for cowhocked and 0.69 (95\% CI: 0.44 to 0.94 ) for hock angles.

Because it would have required video recordings, it was not possible to estimate the intraobserver variation of the lameness scores. From training sessions with 78 completely inexperienced veterinary students, we estimated between-student kappa values to range from approximately 0.3 to $>0.8$ (unpublished data). In a recent Danish study involving 5 untrained observers (dairy veterinarians), the kappa values of lameness and hock lesions were similar to those of the students (between 0.36 and 0.88 ). In addition, it was noticed that the cutoff value between scores had an effect on interobserver agreement and that training may increase the kappa value, as indicated by the kappa values for a trained observer being 0.77 and 0.80 (Thomsen and Baadsgaard, 2006). In a study of reliability and repeatability, observers had high repeatability of locomotion 
Table 2. Prevalence (\%) of conformation traits and lameness scores at different DIM (mean \pm SE)

\begin{tabular}{lcccc}
\hline & \multicolumn{3}{c}{ DIM $^{1}$} \\
\cline { 2 - 5 } & $\begin{array}{c}\leq 0 \\
(\mathrm{n}=96)\end{array}$ & $\begin{array}{c}1 \text { to } 100 \\
(\mathrm{n}=99)\end{array}$ & $\begin{array}{c}101 \text { to } 200 \\
(\mathrm{n}=37)\end{array}$ & $\begin{array}{c}201 \text { to } 300 \\
(\mathrm{n}=22)\end{array}$ \\
\hline $\begin{array}{l}\text { Item } \\
\begin{array}{l}\text { Lameness score } \\
\text { Moderate-severe lameness }(\geq 3)\end{array}\end{array}$ & & & \\
$\begin{array}{l}\text { Conformation traits } \\
\text { Cow-hock }\end{array}$ & $25 \pm 4$ & $50 \pm 5$ & $67 \pm 7$ & $86 \pm 5$ \\
$\quad \begin{array}{l}\text { Abnormal hock angle } \\
\text { Asymmetric claw }\end{array}$ & $81 \pm 4$ & $85 \pm 4$ & $86 \pm 6$ & $86 \pm 7$ \\
Concave toe-wall $\mathrm{RF}^{2}$ & $33 \pm 5$ & $26 \pm 4$ & $19 \pm 6$ & $23 \pm 9$ \\
Concave toe-wall $\mathrm{RR}^{3}$ & $45 \pm 5$ & $68 \pm 5$ & $68 \pm 8$ & $73 \pm 9$ \\
\hline
\end{tabular}

${ }^{1} \mathrm{DIM}=0$ is equivalent to day of calving.

${ }^{2} \mathrm{RF}=$ right front medial claw.

${ }^{3} \mathrm{RR}=$ right rear lateral claw.

score in individual animals (Winckler and Willen, 2001). Consequently, we assumed that within-observer variation was low.

Ideally, the dependent variables in a linear regression analysis should be on a continuous scale. This is clearly not the case with the score values in this study. Whether this discrepancy is a practical problem is addressed by Rummel (1970) and Rutledge and Gunsett (1982). If the number of score categories is very limited (dichotomous at the extreme) the variance will be restricted. If the distribution of the score values is very assymmetrical, the model predictions may be outside the range of the observed values. Residual plots indicated that the truly quantitative variables met model assumptions better than the score values. No severe violations of the assumptions of normal distributions were found. In future studies, effort should be made to use scores with more categories, similar to the linear scores applied in breeding programs. We could have applied a multiplicative model such as polytomous logistic regression (e.g., as applied by Enevoldsen and Sørensen, 1992). However, the interpretation of the results of these analyses is much more complex than for the results from linear regression.

\section{Prevalences of Conformation Traits and Lameness}

The mean DIM at the 5 examinations was $-41,51$, 138,248 , and 386 . The prevalences of the recorded conditions are in Table 2, and most heifers ( $81 \%$ ) were cowhocked before calving. Although the proportion of cows with abnormal hind leg conformation appeared to increase throughout the first lactation, this observation may be an artifact due to selection of cows. The withincow association with DIM is presented in Table 3. Because most heifers were cow-hocked at the first recording, it was not possible to determine the cause-andeffect relation in this study. Heifers may have been born with abnormal conformation or may have developed the cow-hocked posture between birth and the initial scoring for this study. Slippery floors and pain in the claws both may lead to an abnormal cow-hocked stance (Telezhenko and Bergsten, 2005). In a Danish study from 1991, 18\% of 4- to 10-mo-old bulls were cow-hocked (Andersen et al., 1991). If it is possible to extrapolate from bulls to heifers, then a prevalence of $81 \%$ for heifers is problematic. Further studies are warranted to explore reasons for the high prevalence and the effect of cow-hocked posture among young heifers.

Prevalence of abnormal hock angles across herds is shown in Table 2 . The reduction in prevalence of abnormal hocks after calving may be due to culling, claw trimming, and growth. Vermunt and Greenough (1996a) studied 1-yr-old heifers and found that all started with straight hocks and that hock angles decreased with age except in heifers confined indoors on concrete slats. In a Danish study of young bulls (Andersen et al., 1991), the prevalence of abnormal hock angle was $17 \%$. Van Dorp et al. (2004) found that cows with straighter hocks (large hock angles) had genetically better locomotion.

The asymmetry of the claws was severe (both width and length) in $4 \%$ of the heifers (data not shown) and $41 \%$ had asymmetric claws (width or length). The prevalence of asymmetric claws increased from before to after calving and remained high throughout the lactation.

The concavity of 718 toe-walls on front and hind legs were measured. Concave toe-walls occurred in the front legs of $48 \%$ of heifers before calving (Table 2). The mean concavity in the front claws was $1.6 \mathrm{~mm}$ with a maximum of $7.5 \mathrm{~mm}$ and a minimum of $-5.0 \mathrm{~mm}$ (convex). In the hind legs, more than half of the dorsal toe-walls remained straight or even slightly convex at all times throughout lactation. The mean concavity of the hind 
Table 3. Fixed effect estimates (SE in parentheses) of factors with potential relations to lameness and conformation trait scores

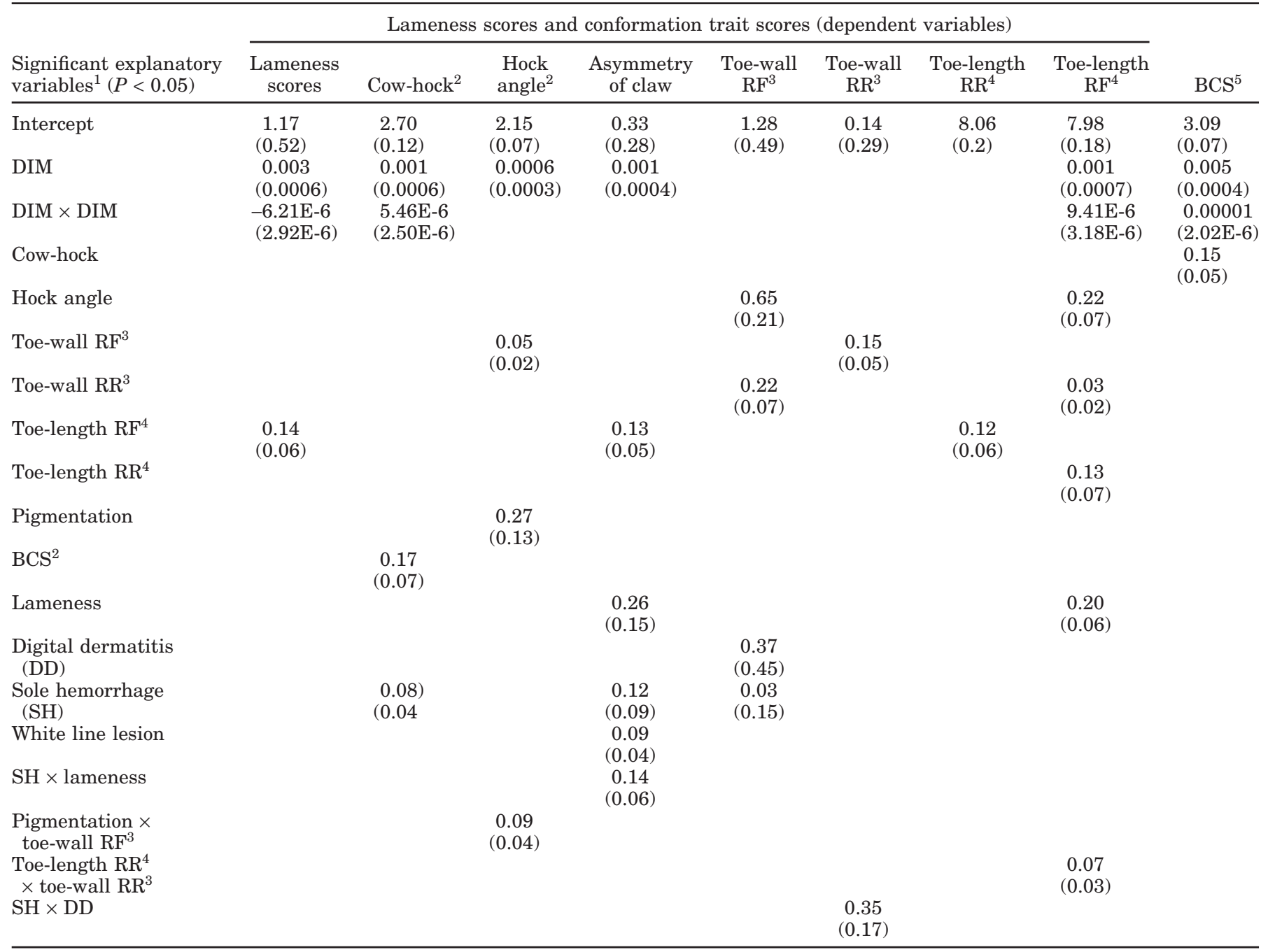

${ }^{1} \mathrm{RF}=$ right front leg; $\mathrm{RR}=$ right rear leg.

${ }^{2}$ Units of the ordinal conformation scores are defined in Table 1.

${ }^{3}$ For the continuous variable toe-wall concavity, 1 unit $=1 \mathrm{~mm}$.

${ }^{4}$ For the continuous variable toe-length, 1 unit $=1 \mathrm{~cm}$.

${ }^{5} \mathrm{BCS}=$ ordinal 1 to 5 score (0.25 increments).

legs was $0.7 \mathrm{~mm}$ with a maximum of $5.0 \mathrm{~mm}$ and a minimum of $-3.0 \mathrm{~mm}$ (i.e., convex).

\section{Multivariable Models}

The cause-and-effect relations were not clear between conformation scores, foot lesions, and lameness. For example, a cow-hocked posture may be both a cause and an effect of a foot lesion. Consequently, it is not obvious which variables to specify as response or explanatory variables. Ideally, one should specify a model in which all variables are response variables (e.g., factor analysis). However, such models may be difficult to interpret. Instead, we chose to explore both possibilities; that is, all the conformation traits and lameness scores described in Table 1 were included as both response and explanatory variables (denoted $\mathrm{X}$ in the methods section above).

Double sole, sole ulcer, and interdigital hyperplasia occurred too infrequently to allow a meaningful multivariable analysis. These conditions were accounted for by creating a pooled variable assigned the value 1 if one or more of the conditions occurred; otherwise the value 0 was assigned. This pooled condition occurred in $10 \%$ of the observations (not shown).

Table 4 shows estimates of total variance and percentage contribution to variance from herd-level, cowlevel, and residual (i.e., within-cow variation or mea- 
Table 4. Total variance and percentage contribution to variance from herd level, cow level, and residual ${ }^{1}$

\begin{tabular}{lcccc}
\hline & \multicolumn{1}{c}{$\begin{array}{c}\text { Total } \\
\text { variance }\end{array}$} & $\begin{array}{c}\text { Herd level, } \% \\
\text { (herd factors) }\end{array}$ & $\begin{array}{c}\text { Cow level, \% } \\
\text { (cow factors) }\end{array}$ & $\begin{array}{c}\text { Residual, \% } \\
\text { (true error } \\
\text { or changes } \\
\text { within cow) }\end{array}$ \\
\hline Cow-hock & $0.28 / 0.27$ & $7 / 7$ & $43 / 41$ & $50 / 52$ \\
Hock angle & $0.27 / 0.26$ & $0 / 4$ & $48 / 50$ & $52 / 46$ \\
Asymmetry of claws & $0.29 / 0.30$ & $1 / 17$ & $17 / 20$ & $82 / 63$ \\
Toe-length RF & $0.50 / 0.44$ & $24 / 25$ & $6 / 2$ & $70 / 73$ \\
Toe-length RR $\mathrm{RR}^{2}$ & $0.54 / 0.50$ & $39 / 38$ & $17 / 14$ & $44 / 48$ \\
Concave toe-wall RF & $3.89 / 3.15$ & $23 / 13$ & $6 / 9$ & $72 / 78$ \\
Concave toe-wall RR & $2.69 / 2.48$ & $18 / 14$ & $17 / 18$ & $65 / 68$ \\
BCS & $0.25 / 0.15$ & $12 / 13$ & $0 / 0$ & $88 / 87$ \\
\hline
\end{tabular}

\footnotetext{
${ }^{1}$ Numbers before the slash are percentage contribution to variance from a 3-level model without fixed effects; numbers after the slash are contributions from the final models. Contributions from the final models are shown in Table 3.

${ }^{2} \mathrm{RF}=$ right front medial claw.

${ }^{3} \mathrm{RR}=$ right rear lateral claw.
}

surement error). In the models the variances are estimated at zero-values of the explanatory variables.

Cow-Hocked Scores. Initially we present a complete description of all the parameters in the model to aid interpretation of Tables 3 and 4 . The intercept value is 2.7. This means that the expected score for cow-hock at the calving date across herds and cows is 2.7. In Table 4 we see that the corresponding total variance is 0.28 . The standard error of the intercept can be estimated as the square root of the total variance, which is 0.53 . That is, $95 \%$ of the expected cow-hock scores at calving can be expected to lie between $2.7 \pm 2 \times 0.53$. Because the herd-level variance is only $7 \%$ of the total variance, the expected herd-level cow-hock scores at calving are very similar to the overall expected value (2.7). In contrast, $43 \%$ of the total variance can be ascribed to the individual cows while $50 \%$ is error (both numbers in Table 4). The relationship between cowhocked score and DIM was quadratic. By means of the parameter estimates in Table 3 , the expected cow hocked score at 300 DIM can be calculated as $2.7+$ $300 \times(-0.001)+300 \times 300 \times(5.46 \mathrm{E}-6)$, or 2.9. A 1 -unit increase in BCS was associated with a 0.17 unit $(-0.17$ as parameter estimate in Table 3 ) decrease in cow-hock scores, irrespective of the other covariates. In other words, thinner cows were generally more likely to be cow-hocked. Explanations could be that the cow-hocked conformation was associated with pain that caused weight loss due to less time spent eating or cow-hocked cows had greater milk yield, thus lowering BCS due to the negative energy balance. A 1-unit increase in sole hemorrhage score was associated with a 0.08 -unit $(0.08$ as parameter estimate in Table 3) increase in cowhocked scores. In other words, sole hemorrhages occurred more frequently in cow-hocked cows. This was an expected finding because the lateral hind claws are usually affected with sole hemorrhages more often than medial claws and the lateral claw bears most weight in the cow-hocked stance. A quadratic relationship existed between DIM and occurrence of cow-hocked scores. Because of the limited amount of data, we were not able to describe a detailed relationship between cow-hocked scores and DIM. The quadratic relationship was the best available option to visualize the association with reasonable precision and should not be interpreted biologically.

Inclusion of the fixed effects had very limited influence on the estimation of variance components. About 7 and $41 \%$ of variance was associated with the herd and cow level, respectively. This result may indicate that herd factors have little effect on cow-hocked scores. The rather large cow-level contribution was expected because the cow-hock trait is heritable, as described in previous studies (Andersen et al., 1991; Brotherstone and Hill, 1991). Because of the limited sample size, estimation of heritability was not meaningful. Because the kappa value of cow-hocked scores was less than 1.0 (0.69), measurement error must have contributed to some of the residual variation. Because the cow-hocked scores are reasonably reproducible within herds, a substantial residual variation may indicate that cowhocked scores are rather dynamic within cows and within each scoring. Consequently, several scorings of individual cattle appear to be needed to classify cattle correctly for this trait.

Hock Angles. Hock angle decreased (sickle hocked) with increasing concavity of the RF toe-wall $(-0.05)$ and in unpigmented claws (0.27). In black claws with a straight toe-wall, the score value increased for straight hock angles $(-0.09)$. One interpretation of these results is that abnormal hock angles may alter the distribution of weight between the front and hind part of the cow 
during standing and walking, thereby disturbing growth and wear in the front claws. In the case of laminitis, the altered weight load may increase the risk of rotation of the distal phalanx and lead to the development of a concave dorsal toewall.

Inclusion of the fixed effects had little impact on the variance components. Herd level contributed only modestly to the variance before and after the fixed effects were included. This result indicates that the herds differed little with respect to hock angle scores. Approximately $50 \%$ of the variance of hock angle was associated with the cow level. The large contribution was expected because other studies have shown that the hock angle trait has considerable heritability (Brotherstone and Hill, 1991). However, some of the residual variation could be due to difficulties in conformation scoring, as indicated by a kappa value of 0.69 for hock angles. Again, some of the residual variance will be due to the hock angle scores changing through time, but several scorings of individual cattle are needed to correctly classify cattle with this trait.

Asymmetry of the Claws. Asymmetry of the claws increased (0.13) with increased toe-length in the RF medial claw. Increased severity of white line lesion was associated with increased claw asymmetry (0.09). The combination of long claws and white line lesion could be due to increased wear of the heel bulb area, and more weight load on the abaxial white line in the sole heel junction. Lameness score $(-0.26)$ and sole hemorrhage $(-0.12)$ appeared to be more severe in symmetric claws. This association may be part of the early stages of a vicious cycle, in which the cow-hocked stance with increased weight load on the sole of the lateral claw leads to asymmetry because of increased growth. This condition increases the risk of claw lesions and pain in the lateral hind claws. When the lateral claws become sore, the cow attempts to relieve the pain by adopting a wider cow-hocked stance, which further increases the weight load on the sole of the lateral hind claws. This cycle continues, increasing the severety of lesions and abnormality of conformation.

The combination of lameness and sole hemorrhage (0.14) was associated with increased asymmetry of the claws. The latter finding fits the theory of the cycle, in which the cow adopts a wide hind-leg stance due to soreness of the lateral hind claw, leading to increased weight load and subsequently growth of the lateral hind claw. This further increases the risk of sole hemorrhage and lameness. Further studies on the dynamics of conformation of claws and legs in lame and nonlame heifers and cows may support our suggestion of a vicious cycle.

Inclusion of the fixed effects had some influence on the estimates of variance at herd-level and residuals. Variation from herd increased from $1 \%$ before including fixed effects to $17 \%$ after including the fixed effects. This between-herd variation in occurrence of asymmetric claws may be caused by differences in trimming, claw wearing, and status of milk production determining the growth of the horn. About $20 \%$ of the variance was associated at the cow level. The occurrence of asymmetric claws cannot be explained easily by the prevalence of foot lesions or abnormal conformation as indicated by the variance contribution from cow-level (20\%). The residual variation contributes with $63 \%$, which is either due to measurement error or that asymmetric claws change between 2 recordings. Because it seems unlikely that the claws shrink occasionally, we must expect some of the residual to be due to scoring errors.

Concave Toe-Walls. A concave dorsal toe-wall on the RF medial claw appeared to increase $(0.22)$ with increased concavity of the toe-wall on the RR lateral claw. Concavity of the RR toe-wall (0.15) was also an explanatory variable for concavity in the RF. Consequently, the 2 variables are closely related. The relationship may suggest that the dorsal toe-wall shape was determined by a systemic cow-level factor.

We found that concavity of RF medial toe-wall decreased (-0.65) with increasing hock angle (sicklehocked); the same relationship was also seen between hock angles and dorsal toe-wall concavity on RF medial claws (-0.05). This indicated that those variables are closely related, but the nature of this relation is unclear.

An increase in severity of sole hemorrhage (0.03) and digital dermatitis (0.37) was associated with increased concavity of the RF toe-wall, whereas in the RR claws, a decrease in concavity of the toe-wall appeared to be associated with the combined effect of sole hemorrhage and digital dermatitis $(-0.35)$. A possible explanation could be that the front claws were more affected by laminitis compared with the hind claws, leading to a concave toe-wall. Because digital dermatitis often affects the hind claws more than the front claws (Murray et al., 1996), digital dermatitis in the hind legs may lead to a greater front-weight overload, due to retraction of the hind limbs to relieve pain in the hind claws.

Including the fixed effects had some effect on the variance of $R F$ toe-wall concavity but considerably less on the RR claw. The herd-level variance for toe-wall was rather similar for $R F$ and $R R$, but a value of about $13 \%$ indicates limited between-herd difference. The contribution to cow-level variance was different between $R F$ and $R R$, with twice as much variation on $R R$. This result may indicate that concavity of RR claws has a genetic component, but, as mentioned above, the limited data do not allow for an analysis to evaluate this hypothesis. The residual variation in RF claws was $78 \%$ and in RR claws was $68 \%$ and may be due to measurement errors caused by conditions such as cork- 
screw claw or hard manure embedded in the toe-wall. Such factors would lead to changes between 2 scorings, but, in reality, are measurement errors.

Toe-Length. Toe-length in the RF medial (0.13) and the RR lateral claw (0.12) are explanatory factors for each other. An increase in length on the RR claws was associated with increased length on the RF claws. This relationship was expected even though differences existed in growth rate between front and hind claws. The combination of RR toe-length and concavity of RR claw (0.07) appeared to further increase the length of the $\mathrm{RF}$ claw. Toe-length in the RF claw (0.22) appeared to increase with increased hock angle. The probable explanation may be that front leg conformation of sickle-hocked cattle was altered as well as hind leg conformation, causing less wear in the toes of all legs. This assumption cannot be confirmed because front leg conformation was not recorded. However, studies of front leg conformation show heritability as large as for hind leg conformation (Baumgartner and Distl, 1990; Huang and Shanks, 1995). Long toes in the RF claws are associated with increased lameness scores $(0.2)$ and lameness scores increased (0.14) with long RF claws. The data here provide no way of exploring whether this is due to lame cows having reduced wear because of lack of activity or that long claws give the impression that the cows are lame or that long claws are painful, causing lameness. Nevertheless, this finding emphasizes the need for frequent claw trimming.

The inclusion of fixed effects in the model had very little effect on the estimates of variance components for either toe-length in RF or RR claws. The herd level variances were 38 and $25 \%$ for $R R$ and $R F$ toe-length, respectively. We would expect large differences between herds due to claw trimming practices or different floor properties. Differences in growth are also likely. Cow-level variance is much greater for RR claws than for RF claws. This result could occur if horn quality in the $R R$ was affected by the environment differently than the RF. The residual variance for toe-length in RR claws was $48 \%$ and in RF claws was $73 \%$. We would expect the toe-length to change between each recording and explain most of the residual variation because little measurement error is likely.

$\boldsymbol{B C S}$. Increases in BCS were related to parallel hind legs (-0.15), as described for the cow-hocked animals. Alternatively, cows with less milk yield have better conformation and are less likely to lose weight during lactation. The relation between BCS and conformation is described by others (Manson and Leaver, 1989; Wells et al., 1993; Van Dorp et al., 2004).

Inclusion of fixed effects reduced the total variance considerably (40\%), but had no effect on the relative components of variance. The herd-level variance of BSC was approximately $13 \%$. Measurement errors may have been large because heifers before calving, according to the authors' experience, are more difficult to score. The limited sample size in this study and a rather narrow range of the measurement scale ( 1 to 4 ) may also have led to overparameterization of the model.

\section{CONCLUSIONS}

The majority of heifers had abnormal leg and claw conformation before calving. Cow-hocked conformation was associated with poor body condition. Abnormal hind leg conformation and asymmetry of the claws were associated with sole hemorrhages, white line lesion, and lameness. Cow-hocked stance appeared to lead to increased weight load on the lateral hind claw, which may subsequently lead to asymmetric claws due to overload, growth, and claw lesions. Cow-hocked conformation may thus increase the risk of claw lesions and lameness. When a cow attempts to relieve pain by adopting a cow-hocked stance, the weight shifts to the sole of the lateral claw and the risk of lesions increases further. Without intervention, this cycle of events continues with more severe lesions and conformation changes. The results of the study indicate that a vicious cycle may be initiated by sole hemorrhages and lameness occurring in symmetric claws. Further studies on the risk factors, the dynamics, and repeatability of conformation scores and the effect of precalving conformation are necessary.

\section{ACKNOWLEDGMENTS}

The authors wish to thank the farmers and claw trimmers for their help and cooperation. The project received additional funding from the Danish Agricultural Advisory Service, National Centre, Denmark, and the Hans Kiers Fund.

\section{REFERENCES}

Andersen, B. B., P. Madsen, and H. H. Smedegaard. 1991. Genetic analysis of claw and leg traits in young bulls. Rep. 701 from the Natl. Institute of Anim. Sci., Foulum, Denmark.

Baumgartner, C., and O. Distl. 1990. Correlations between sires and daughter and selection for improved structural claw soundness. Pages 199-218 in Proc. 6th Int. Symp. Disorders of the Ruminant Digit. Univ. Liverpool, UK.

Bennedsgaard, T. W., C. Enevoldsen, S. M. Thamsborg, and M. Vaarst. 2003. Effect of mastitis treatment and somatic cell counts on milk yield in Danish organic dairy cows. J. Dairy Sci. 86:3174-3183.

Bergsten, C. 1994. Haemorrhages of the sole horn of dairy cows as a retrospective indicator of laminitis: An epidemiological study. Acta Vet. Scand. 35:55-66.

Boettcher, P. J., J. C. M. Dekkers, L. D. Warnick, and S. J. Wells. 1998. Genetic analysis of clinical lameness in dairy cattle. J. Dairy Sci. 81:1148-1156. 
Brotherstone, S., and W. G. Hill. 1991. Dairy-herd life in relation to linear type traits and production. 2. Genetic analyses for pedigree and non-pedigree cows. Anim. Prod. 53:289-297.

Enevoldsen, C., Y. T. Grohn, and I. Thysen. 1991. Sole ulcers in dairy cattle-Associations with season, cow characteristics, disease, and production. J. Dairy Sci. 74:1284-1298.

Enevoldsen, C., and J. T. Sørensen. 1992. Effects of the dry period length on clinical mastitis and other major clinical health disorders. J. Dairy Sci. 75:1007-1014.

Ferguson, J. D., D. T. Galligan, and N. Thomsen. 1994. Principal descriptors of body condition score in Holstein cows. J. Dairy Sci. 77:2695-2703.

Green, L. E., V. J. Hedges, Y. H. Schukken, R. W. Blowey, and A. J. Packington. 2002. The impact of clinical lameness on the milk yield of dairy cows. J. Dairy Sci. 85:2250-2256.

Hernandez, J., J. K. Shearer, and D. W. Webb. 2001. Effect of lameness on the calving-to-conception interval in dairy cows. J. Am. Vet. Med. Assoc. 218:1611-1614.

Huang, Y., and R. Shanks. 1995. Within-herd estimates of heritabilities for six hoof characteristics and impact of dispersion of discrete severity scores on estimates. Livest. Prod. Sci. 44:107-114.

Jubb, T. F., and J. Malmo. 1991. Lesions causing lameness requiring veterinary treatment in pasture-fed dairy cows in East Gippsland. Aust. Vet. J. 68:21-24.

Kossaibati, M. A., and R. J. Esslemont. 1997. The costs of production diseases in dairy herds in England. Br. Vet. J. 154:41-51.

Le Fevre, A. M., D. N. Logue, J. E. Offer, I. McKendrick, and G. Gettinby. 2001. Correlations of measurements of subclinical claw horn lesions in dairy cattle. Vet. Rec. 148:135-138.

Manson, F. J., and J. D. Leaver. 1989. The effect of concentrate:silage ratio and of hoof trimming on lameness in dairy cattle. Anim. Prod. 49:15-22.

Murray, R. D., D. Y. Downham, M. J. Clarkson, W. B. Faull, J. W. Hughes, F. J. Manson, J. B. Merritt, W. B. Russell, J. E. Sutherst, and W. R. Ward. 1996. Epidemiology of lameness in dairy cattle: Description and analysis of foot lesions. Vet. Rec. 138:586-591.

O'Callaghan, K. A., P. J. Cripps, D. Y. Downham, and R. D. Murray. 2003. Subjective and objective assessment of pain and discomfort due to lameness in dairy cattle. Anim. Welf. 12:605-610.

Peterse, D. J. 1985. Laminitis and interdigital dermatitis and heel horn erosion-A European perspective. Pages 83-91 in The Veter- inary Clinics of North America-Food Animal Practice symposium on bovine lameness and orthopedics. Vol. 1. 1st ed. D. Ramanauskas, J. G. Ferguson, ed. WB Saunders Co., Philadelphia, PA.

Rummel, R. J. 1970. Applied Factor Analysis. Northwestern Univ. Press, Evanston, IL.

Rutledge, J. J., and F. C. Gunsett. 1982. Analysis of categorical data in the animal sciences. J. Anim. Sci. 54:1072-1078.

SAS Institute. 2000. The SAS System for Windows. V8. SAS Inst. Inc., Cary, NC.

Sprecher, D. J., D. E. Hostetler, and J. B. Kaneene. 1997. A lameness scoring system that uses posture and gait to predict dairy cattle reproductive performance. Theriogenology 47:1179-1187.

Telezhenko, E., and C. Bergsten. 2005. Influence of floor type on the locomotion of dairy cows. Appl. Anim. Behav. Sci. 93:183-197.

Thomsen, P. T., and N. P. Baadsgaard. 2006. Intra- and inter-observer agreement of a protocol for clinical examination of dairy cows. Prev. Vet. Med. 75:133-139.

Toussaint-Raven, E. 1985. Structure and functions. Pages 27-34 in Cattle Footcare and Claw Trimming. Farming Press Books, Ipswich, UK.

van der Tol, P. P. J., J. H. M. Metz, E. N. Noordhuizen-Stassen, W. Back, C. R. Braam, and W. A. Weijs. 2002. The pressure distribution under the bovine claw during square standing on a flat substrate. J. Dairy Sci. 85:1476-1481.

Van Dorp, T. E., P. Boettcher, and L. R. Schaeffer. 2004. Genetics of locomotion. Livest. Prod. Sci. 90:247-253.

Vermunt, J. J., and P. R. Greenough. 1996a. Hock angles of dairy heifers in two management systems. Br. Vet. J. 152:237-242.

Vermunt, J. J., and P. R. Greenough. 1996b. Sole haemorrhages in dairy heifers managed under different underfoot and environmental conditions. Br. Vet. J. 152:57-73.

Wells, S. J., A. M. Trent, W. E. Marsh, P. G. McGovern, and R. A. Robinson. 1993. Individual cow risk-factors for clinical lameness in lactating dairy-cows. Prev. Vet. Med. 17:95-109.

Winckler, C., and S. Willen. 2001. The reliability and repeatability of a lameness scoring system for use as an indicator of welfare in dairy cattle. Acta Agric. Scand. A. Anim. Sci. Suppl. 30:103-107.

Woodward, M. 1999. Basic analytical procedures. Pages 31-101 in Epidemiology: Study design and data analysis. C. Chatfield, and J. V. Zidek, ed. CRC Press, Boca Raton, FL. 